\title{
The role of aplysia ras homolog $I$ in colon cancer cell invasion and adhesion
}

\author{
JUN OUYANG $^{1}$, XIAOHUI PAN ${ }^{2}$ and ZECHENG HU ${ }^{1}$ \\ Departments of ${ }^{1}$ Gastrointestinal Surgery and ${ }^{2}$ Urology, The First Affiliated Hospital \\ of University of South China, Hengyang, Hunan 421001, P.R. China
}

Received August 16, 2016; Accepted May 5, 2017

DOI: $10.3892 /$ etm.2017.5122

\begin{abstract}
Aplysia ras homolog I (ARHI) acts as a tumor suppressor in certain cancer cells. However, the role of ARHI in colon cancer development has not previously been reported. The present study aimed to investigate the functional role of ARHI in colon cancer focusing on the aspect of metastasis. Furthermore, the molecular mechanism underlying its function was explored. The present study detected the expression of ARHI in a human colon epithelial cell line and colon cancer cell lines using reverse transcription-quantitative polymerase chain reaction and western blotting analysis. It was demonstrated that ARHI expression was significantly downregulated in colon cancer cell lines compared with the normal colon epithelial cell line $(\mathrm{P}<0.05)$. An ARHI-pcDNA3.1 plasmid was transfected into HCT116 cells to overexpress ARHI. The number of invaded cells and the adhesive ability were significantly decreased in the ARHI overexpression group compared with the control group, as determined by cell invasion and adhesion assays $(\mathrm{P}<0.05)$. Furthermore, ARHI overexpression led to increased mRNA and protein expression levels of E-cadherin, and decreased mRNA and protein expression levels of $\mathrm{N}$-cadherin and vimentin. Wnt/ $\beta$-catenin signaling was suppressed in HCT116 cells overexpressing ARHI. Lithium chloride, a wnt/ $\beta$-catenin signaling activator, was able to attenuate the effect of ARHI on HCT116 cell invasion and adhesion. In addition, the effect of ARHI on epithelial-mesenchymal transition (EMT) in HCT116 cells was reversed by the activation of wnt/ $\beta$-catenin signaling. In conclusion, the present study provided novel evidence that ARHI could inhibit colon cancer cell invasion and adhesion through suppressing EMT, and these effects were achieved, at least partially, via the suppression of the wnt/ $\beta$-catenin signaling pathway. The
\end{abstract}

Correspondence to: Dr Jun Ouyang, Department of Gastrointestinal Surgery, The First Affiliated Hospital of University of South China, 69 Chuanshan Road, Hengyang, Hunan 421001, P.R. China

E-mail: oyj1973@yeah.net

Key words: aplysia ras homolog I, colon cancer, metastasis, epithelial-mesenchymal transition, wnt $/ \beta$-catenin present findings may help in developing novel therapeutic approaches for colon cancer.

\section{Introduction}

Colon cancer is one of the most common malignancies in the gastrointestinal tract (1). Every year, $>1$ million people are diagnosed with colorectal cancer, accounting for $\sim 10 \%$ of all cancer types (2). Treatments used for colon cancer includes various combinations of surgery, radiation therapy, chemotherapy and targeted therapy (3). Colon cancer that is confined within the colon, and may be curable with surgery; however, cancer that has spread widely typically has a poor prognosis and is usually not curable (4). Therefore, it is necessary to identify the molecular mechanism involved in metastasis, and the identification of novel approaches for the diagnosis and treatment of colon cancer is urgent.

Aplysia ras homolog I (ARHI) is a member of the ras superfamily, with 55-62\% homology to Ras and Rap (5). Notably, in contrast to Ras, ARHI acts as a tumor suppressor in various cancer types by inhibiting cell growth, motility and invasion (6-10). A study by Wang et al (11) reported that low expression of ARHI was observed in $61.7 \%$ of human colon cancer specimens, and the ARHI expression level in colon cancer tissues was markedly lower than that in the paired non-cancerous tissues. However, the role of ARHI in colon cancer development has not previously been reported.

The majority of mortalities as a result of colon cancer are associated with metastasis (4). Epithelial-mesenchymal transition (EMT) is a well-coordinated process that is necessary for metastasis of epithelial cancer types $(12,13)$. The wnt/ $\beta$-catenin signaling pathway has crucial roles in tumor metastasis, and it is involved in regulating EMT (14-16).

In the present study, an in vitro investigation was conducted to explore the functional role of ARHI in colon cancer, focusing on the aspect of metastasis. Furthermore, the molecular mechanism underlying the function of ARHI was investigated.

\section{Materials and methods}

Cell culture and transfection. A human colon epithelial cell line (FHC) and four colon cancer cell lines (LoVo, HCT116, HT-29 and SW620) were purchased from American Type 
Culture Collection (Manassas, VA, USA). Cells were cultured in Dulbecco's modified Eagle medium (DMEM; Invitrogen; Thermo Fisher Scientific, Inc., Waltham, MA, USA) supplemented with $10 \%$ fetal bovine serum (FBS; Invitrogen; Thermo Fisher Scientific, Inc.) at $37^{\circ} \mathrm{C}$ in a humidified atmosphere of $5 \% \mathrm{CO}_{2}$. To activate the wnt $/ \beta$-catenin signaling pathway in HCT116 cells, the cells were treated with $20 \mathrm{mM}$ lithium chloride (LiCl; Sigma-Aldrich; Merck KGaA, Darmstadt, Germany) for $24 \mathrm{~h}$. Also, an ARHI-pcDNA3.1 plasmid (100 ng; Shenzhen Zhonghong Boyuan Biological Technology Co., Ltd., Shenzhen, China) or empty vector pcDNA3.1 plasmid (100 ng; Shenzhen Zhonghong Boyuan Biological Technology Co., Ltd.) was transfected into the HCT116 cells using Lipofectamine 2000 (Invitrogen; Thermo Fisher Scientific, Inc.), according to the manufacturer's instructions. Transfection with an empty vector was considered the control.

Reverse transcription-quantitative polymerase chain reaction (RT- $q P C R)$. Total RNA was isolated from FHC, LoVo, HCT116, HT-29 and SW620 cells using TRIzol Reagent (Invitrogen; Thermo Fisher Scientific, Inc.). Total RNA (2 $\mu \mathrm{g})$ was used as a template to generate cDNA using a PrimeScript First Strand cDNA Synthesis kit (Takara Bio, Inc., Otsu, Japan), according to the manufacturer's instructions. The primers (Sangon Biotech Co., Ltd., Shanghai, China) used are demonstrated in Table I. qPCR was performed using a KiCqStart SYBR Green qPCR ReadyMix (Sigma-Aldrich; Merck KGaA), according to the manufacturer's instructions, on a Bio-Rad iQ5 Real-Time PCR system (Bio-Rad Laboratories, Inc., Hercules, CA, USA). All samples were analyzed in triplicate. Reactions were performed for $10 \mathrm{~min}$ at $94^{\circ} \mathrm{C}$ followed by 40 cycles of $20 \mathrm{sec}$ at $94^{\circ} \mathrm{C}$ and $1 \mathrm{~min}$ at $59^{\circ} \mathrm{C}$. The relative mRNA expression levels were calculated using the $2^{-\triangle \Delta C q}$ method (17) and normalized to the control, $\beta$-actin.

Western blot analysis. FHC, LoVo, HCT116, HT-29 and SW620 cells were washed with phosphate-buffered saline and lysed using cell lysis buffer (Beyotime Institute of Biotechnology, Haimen, China). Protein concentrations were determined by the Bradford method, using a Bradford Protein Assay kit (Beyotime Institute of Biotechnology). Equal amounts of proteins (20 ug) were separated by $10 \%$ SDS-PAGE. The separated proteins were then transferred to polyvinylidene fluoride membranes (EMD Millipore, Billerica, MA, USA). The membranes were blocked with $3 \%$ bovine serum albumin (BSA; Sigma-Aldrich; Merck KGaA) at $4^{\circ} \mathrm{C}$ overnight, and immunoblotted with the following primary antibodies at $37^{\circ} \mathrm{C}$ for $2 \mathrm{~h}$ : Rabbit polyclonal antibody for ARHI (1:400; ab107051; Abcam, Cambridge, MA, USA); rabbit polyclonal antibody for E-cadherin (1:800; ab15148; Abcam); rabbit polyclonal antibody for N-cadherin (1:400; ab18203; Abcam); rabbit polyclonal antibody for vimentin (1:500; ab137321; Abcam); rabbit polyclonal antibody for wnt3a (1:500; ab28472; Abcam); rabbit polyclonal antibody for Axin 2 (1:1,000; ab107613; Abcam); rabbit polyclonal antibody for $\beta$-catenin (1:400; sc-7199; Santa Cruz Biotechnology, Inc., Dallas, TX, USA); rabbit polyclonal antibody for c-Myc (1:500; sc-788; Santa Cruz Biotechnology, Inc.); rabbit polyclonal antibody for cyclin D1 (1:400; sc-718; Santa Cruz Biotechnology, Inc.); and rabbit polyclonal antibody for $\beta$-actin (1:1,000; ab8227; Abcam). Subsequently, the membranes were washed with Tris-buffered saline-Tween 20 three times and then incubated with goat anti-rabbit immunoglobulin $\mathrm{G}$ conjugated with horseradish peroxidase $(1: 2,000$; A00098; GenScript Co., Ltd., Nanjing, China) at $37^{\circ} \mathrm{C}$ for $1 \mathrm{~h}$. Signals were detected using an enhanced chemiluminescent western blotting substrate (Pierce; Thermo Fisher Scientific, Inc.). The band density was quantified with ImageJ 1.37 software (National Institutes of Health, Bethesda, MD, USA). The protein level was normalized to $\beta$-actin.

Cell invasion assay. Matrigel (BD Biosciences, Franklin Lakes, NJ, USA) was loaded into the upper well of Transwell chambers $(8-\mu \mathrm{m}$ pore size; Corning, Inc., Corning, NY, USA) and incubated at $37^{\circ} \mathrm{C}$ for $30 \mathrm{~min}$. HCT116 cells $\left(5 \times 10^{4}\right.$ cells $\left./ \mathrm{ml}\right)$ were resuspended in DMEM supplemented with $0.5 \%$ BSA, and were loaded into the upper well of the Transwell chamber. The lower well was filled with $1 \mathrm{ml}$ DMEM supplemented with 10\% FBS. Following incubation at $37^{\circ} \mathrm{C}$ for $12 \mathrm{~h}$, the non-invaded cells on the top of the membrane were removed using a cotton swab. The cells invading on the lower face of the membrane were fixed with $95 \%$ ethanol and stained with hematoxylin (Beyotime Institute of Biotechnology) at room temperature for $10 \mathrm{~min}$. The stained cells were then counted under an inverted microscope (TS100; Nikon Corp., Tokyo, Japan) at a magnification of $\mathrm{x} 400$.

Cell adhesion assay. Fibronectin solutions (100 $\mu \mathrm{l}$; Sigma-Aldrich; Merck KGaA) were loaded into 96-well plates and incubated at $37^{\circ} \mathrm{C}$ for $2 \mathrm{~h}$. The plates were blocked with $1 \%$ BSA (Sigma-Aldrich; Merck KGaA) at $37^{\circ} \mathrm{C}$ for $2 \mathrm{~h}$. HCT116 cells $\left(3 \times 10^{5}\right.$ cells $\left./ \mathrm{ml}\right)$ were resuspended in DMEM without serum, and were loaded into the 96-well plates. Following incubation at $37^{\circ} \mathrm{C}$ for $2 \mathrm{~h}$, the adhesive cells were fixed with $4 \%$ paraformaldehyde for $30 \mathrm{~min}$ and stained with $0.5 \%$ crystal violet (Beyotime Institute of Biotechnology) for $2 \mathrm{~h}$ at room temperature. A total of $100 \mu \mathrm{l}$ SDS solution (2\%; Sigma-Aldrich; Merck KGaA) was added into each well to dissolve the crystals. The absorbance at $570 \mathrm{~nm}$ was measured using a microplate reader (Bio-Rad Laboratories, Inc.).

Statistical analysis. All data were expressed as the mean \pm standard deviation. Statistical analysis was performed using SPSS v. 19.0 statistical software (IBM Corp., Armonk, NY, USA). The difference between two groups was determined by Student's t-tests, and the difference among multiple groups was determined by one-way analysis of variance followed by the least significant difference test. $\mathrm{P}<0.05$ was considered to indicate a statistically significant difference.

\section{Results}

Expression of ARHI in colon cancer cell lines. The expression levels of ARHI mRNA and protein in a human colon epithelial cell line (FHC) and four colon cancer cell lines (LoVo, HCT116, HT-29 and SW620) were detected. As demonstrated in Fig. 1, the relative mRNA expression level was significantly decreased in SW620 $(\mathrm{P}<0.05)$, HCT116, HT-29 and LoVo cells (all $\mathrm{P}<0.01)$ compared with the normal colon epithelial 
cell line, FHC. The protein expression levels of ARHI were also significantly decreased in the four colon cancer cell lines compared with the normal colon epithelial cell line $(\mathrm{P}<0.01)$.

Effect of ARHI on HCT116 cell invasion and adhesion. An ARHI overexpression plasmid was created and transfected into HCT116 cells. As demonstrated in Fig. 2A, the relative protein expression level of ARHI was significantly increased in HCT116 cells following transfection with the ARHI-pcDNA3.1 plasmid compared with the control $(\mathrm{P}<0.01)$. Furthermore, the number of invaded cells and the adhesion activity of HCT116 cells were significantly decreased in the ARHI overexpression group compared with the control group $(\mathrm{P}<0.05$; Fig. 2B and $\mathrm{C})$.

Effect of ARHI on EMT markers in HCT116 cells. Subsequently, the effect of ARHI on EMT-like phenotypic changes in HCT116 cells was examined. As determined by RT-qPCR and western blot analysis, the relative mRNA and protein expression levels of epithelial marker, E-cadherin, was significantly increased in the ARHI overexpression group compared with the control group $(\mathrm{P}<0.05$; Fig. 3$)$. By contrast, the relative mRNA and protein expression levels of mesenchymal markers, including $\mathrm{N}$-cadherin and vimentin, were significantly decreased in the ARHI overexpression group compared with the control group $(\mathrm{P}<0.05$; Fig. 3).

Effect of ARHI on wnt/ $\beta$-catenin signaling in HCT116 cells. To investigate the effect of ARHI on wnt/ $\beta$-catenin signaling in HCT116 cells, the alterations of wnt $3 \mathrm{a}$ and $\beta$-catenin, as well as the important downstream targets of $\mathrm{wnt} / \beta$-catenin signaling, including Axin 2, c-Myc and cyclin D1, at the mRNA and protein levels were examined. As demonstrated in Fig. 4, ARHI overexpression significantly downregulated the relative mRNA and protein expression levels of wnt3a, $\beta$-catenin, Axin 2, c-Myc and cyclin D1 $(\mathrm{P}<0.05)$.

Activation of wnt/ $\beta$-catenin signaling attenuates the effect of ARHI on HCT116 cell invasion and adhesion. To activate wnt $/ \beta$-catenin signaling in HCT116 cells, the cells were treated with $\mathrm{LiCl}$. As demonstrated in Fig. 5A, the relative protein expression levels of wnt $3 \mathrm{a}$ and $\beta$-catenin were significantly increased in HCT116 cells overexpressing ARHI following $\mathrm{LiCl}$ treatment compared with HCT116 cells overexpressing ARHI without $\mathrm{LiCl}$ treatment $(\mathrm{P}<0.01)$. It was demonstrated that the suppressed cell invasive ability and cell adhesion activity induced by ARHI overexpression were significantly reversed following $\mathrm{LiCl}$ treatment $(\mathrm{P}<0.05$ and $\mathrm{P}<0.01$, respectively; Fig. 5B and C).

Activation of wnt/ $\beta$-catenin signaling attenuates the effect of ARHI on EMT in HCT116 cells. The results of RT-qPCR and western blot analyses demonstrated that ARHI overexpression significantly increased the mRNA and protein expression levels of E-cadherin compared with the control $(\mathrm{P}<0.05)$; however, this effect was significantly attenuated by $\mathrm{LiCl}$ treatment $(\mathrm{P}<0.05$; Fig. 6$)$. The suppressive effect of ARHI on N-cadherin and vimentin mRNA and protein expression was also significantly reversed by $\mathrm{LiCl}$ treatment $(\mathrm{P}<0.05$; Fig. 6).
Table I. Primers used in reverse transcription-quantitative polymerase chain reaction.

\begin{tabular}{lll}
\hline & \multicolumn{2}{c}{ Primer sequence (5'-3') } \\
\cline { 2 - 3 } Gene & \multicolumn{1}{c}{ Sense } & \multicolumn{1}{c}{ Antisense } \\
\hline Aplysia ras & atgcctgttacccacactcc & acgaaccaagcagcctagaa \\
homolog I & & \\
E-cadherin & tgcccagaaaatgaaaaagg & gtgtatgtggcaatgcgttc \\
N-cadherin & aggggacctttcctcaaga & tcaaatgaaaccgggctatc \\
Vimentin & gagaactttgccgttgaagc & tccagcagcttcctgtaggt \\
Wnt3a & ctcccacaccgtcaggtact & acgggacgagaggcttctat \\
$\beta$-catenin & gaaaatccagcgtggacaat & cctcaggattgcctttacca \\
Axin2 & cccaggttgatcctgtgact & aggtgtgtggaggaaaggtg \\
c-Myc & ttcgggtagtggaaaaccag & agcagctcgaatttcttcca \\
Cyclin D1 & gaggaagaggaggaggagga & agagatggaagggggaaaga \\
$\beta$-actin & agagctacgagctgcctgac & agcactgtgttggcgtacag
\end{tabular}
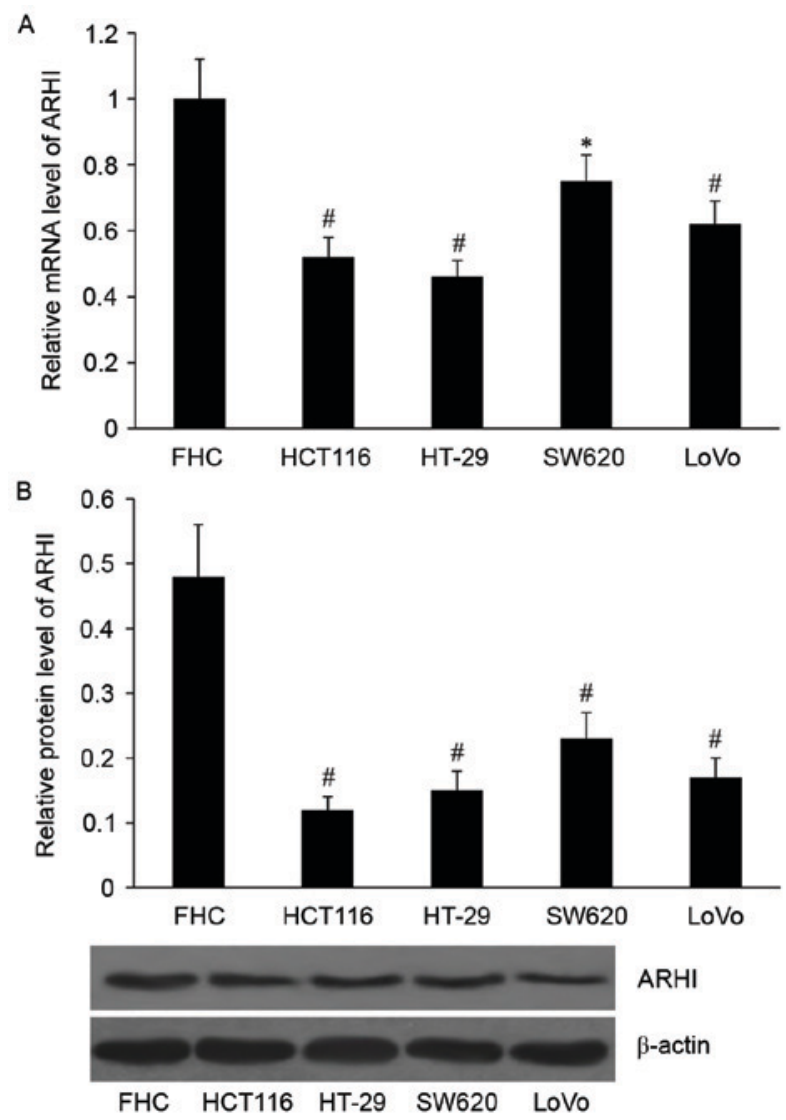

Figure 1. Expression of ARHI in colon cancer cell lines. (A) Relative mRNA expression level of ARHI. (B) Relative protein expression level of ARHI. Expression levels are relative to $\beta$-actin. Data are expressed as the mean + standard deviation $(\mathrm{n}=3) .{ }^{*} \mathrm{P}<0.05$ and ${ }^{~} \mathrm{P}<0.01$ vs. FHC. ARHI, aplysia ras homolog I.

\section{Discussion}

ARHI has been suggested to be a tumor suppressor in various cancer cells $(7,8,10,18)$. A study by Li et al (19) reported that ARHI expression was significantly downregulated in breast 

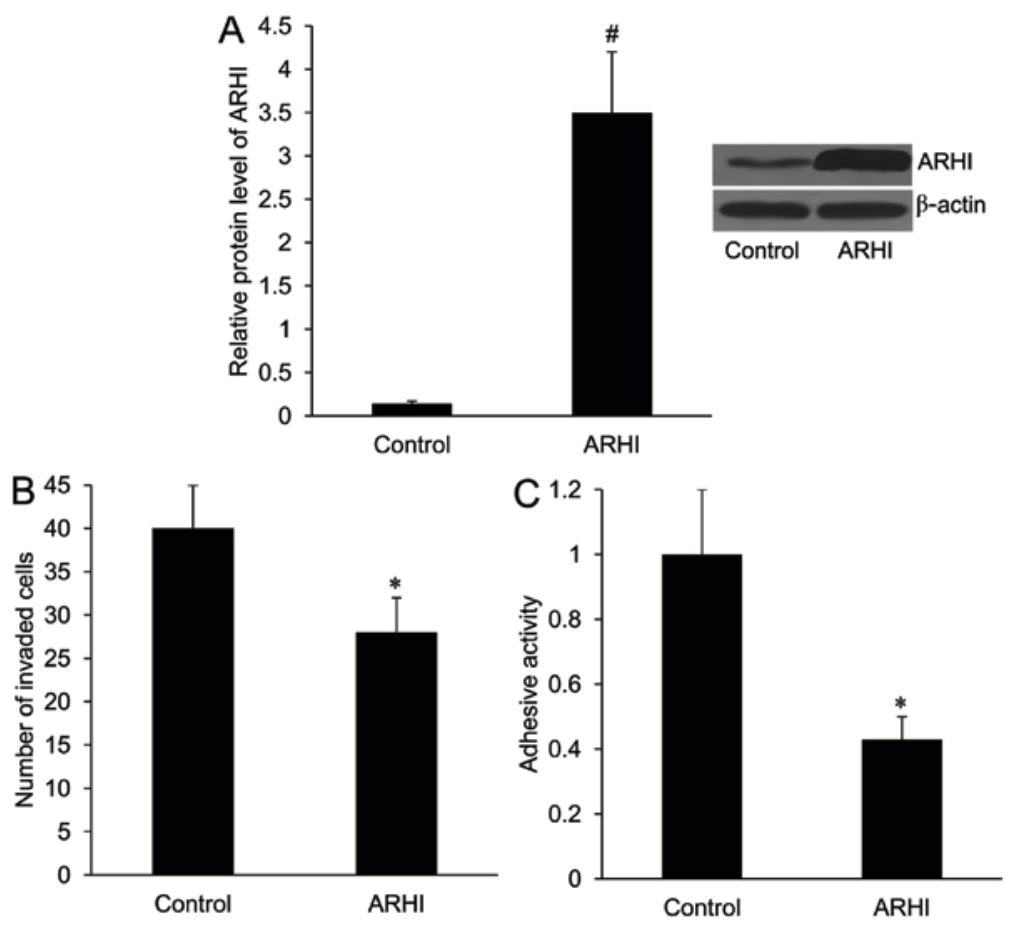

Figure 2. Effect of ARHI on HCT116 cell invasion and adhesion. (A) Protein expression level of ARHI in HCT116 cells, relative to $\beta$-actin, following transfection with the ARHI-pcDNA3.1 plasmid and the control. (B) Cell invasion ability of HCT116 cells following transfection with the ARHI-pcDNA3.1 plasmid and the control. (C) Cell adhesion ability of HCT116 cells following transfection with the ARHI-pcDNA3.1 plasmid and the control. Data are expressed as the mean + standard deviation. ${ }^{*} \mathrm{P}<0.05$ and ${ }^{\#} \mathrm{P}<0.01$ vs. the control. ARHI, aplysia ras homolog I.
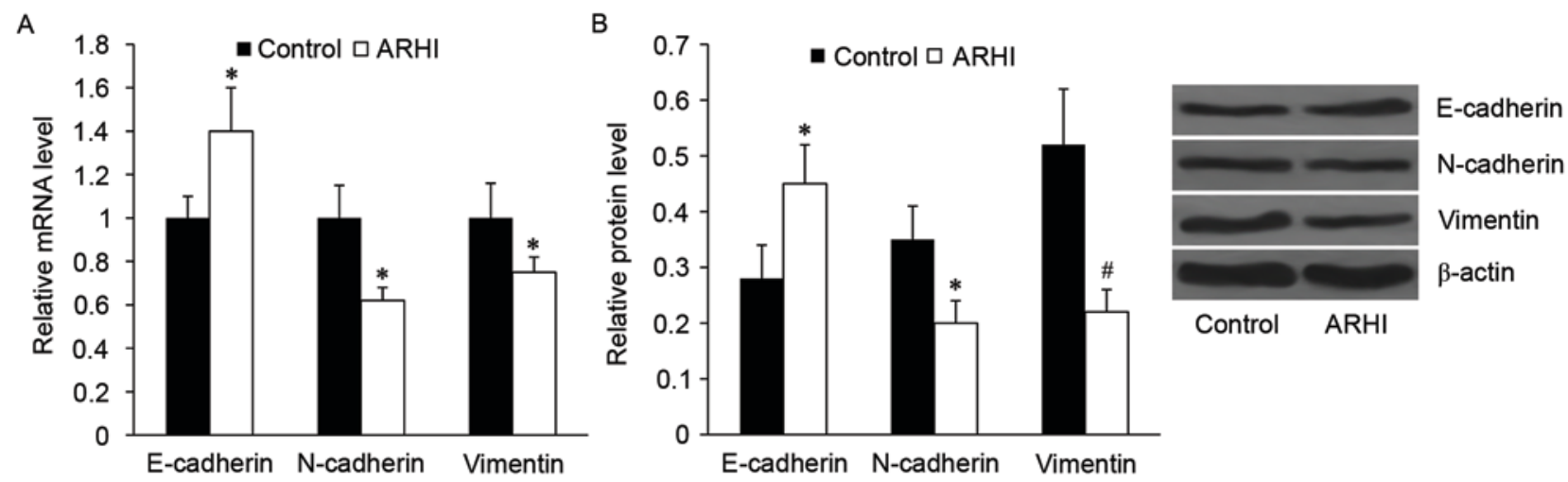

Figure 3. Effect of ARHI overexpression on EMT markers in HCT116 cells. (A) Relative mRNA expression levels of EMT markers. (B) Relative protein expression levels of EMT markers. Expression levels are relative to $\beta$-actin. Data are expressed as the mean + standard deviation $(\mathrm{n}=3)$. ${ }^{*} \mathrm{P}<0.05$ and ${ }^{\#} \mathrm{P}<0.01$ vs. the control. ARHI, aplysia ras homolog I; EMT, epithelial-mesenchymal transition.

cancer cells in comparison to normal breast tissues. Similar results were demonstrated in ovarian, renal, gastric and colon cancer cells $(10,11,20,21)$. Loss of ARHI expression is associated with the decreased ability to inhibit cell growth, thus contributing to the development of breast and ovarian cancer (6). Re-expression of ARHI may suppress the clonogenic growth of breast and ovarian cancer cells via downregulation of cyclin D1 promoter activity and inducing $\mathrm{p} 21^{(\mathrm{WAF} / \mathrm{CIPI})}$ expression (18). Furthermore, overexpression of ARHI is associated with the motility and invasiveness of glioma and lung cancer cells $(7,8)$. However, the function of ARHI in colon cancer is unclear. The present study, for the first time, detected the expression of ARHI in human colon cancer cell lines. Consistent with the results in colon cancer tissues and other cancer cells, it was demonstrated that ARHI expression was significantly downregulated in a series of human colon cancer cell lines compared with the normal colon epithelial cell line. These results indicated that ARHI may be involved in the development of colon cancer. Convincing evidence has been provided that cancer cell invasion and adhesion are related to cancer progression and therapy efficacy (22). Subsequently, the present study utilized gain-of-function experiments on the HCT116 cell line, which demonstrated the lowest ARHI expression among these colon cell lines, to investigate the effect of ARHI on colon cancer cell invasion and adhesion. To the best of our knowledge, the present study provided the first evidence that ARHI could inhibit colon cancer cell invasion and adhesion, thus contributing to the suppression of colon cell metastasis. 

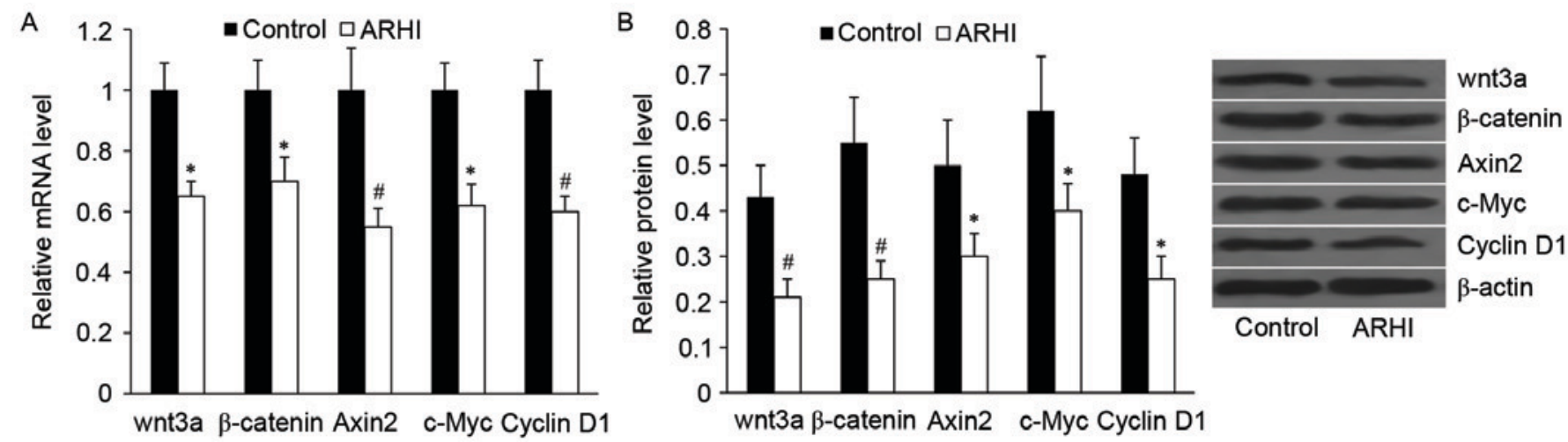

Figure 4. Effect of ARHI overexpression on wnt/ $\beta$-catenin signaling in HCT116 cells. (A) Relative mRNA expression levels of members of the wnt/ $\beta$-catenin signaling pathway. (B) Relative protein expression levels of members of the wnt/ $\beta$-catenin signaling pathway. Expression levels are relative to $\beta$-actin. Data are expressed as the mean + standard deviation $(n=3) .{ }^{*} \mathrm{P}<0.05$ and ${ }^{\#} \mathrm{P}<0.01$ vs. the control. ARHI, aplysia ras homolog I.
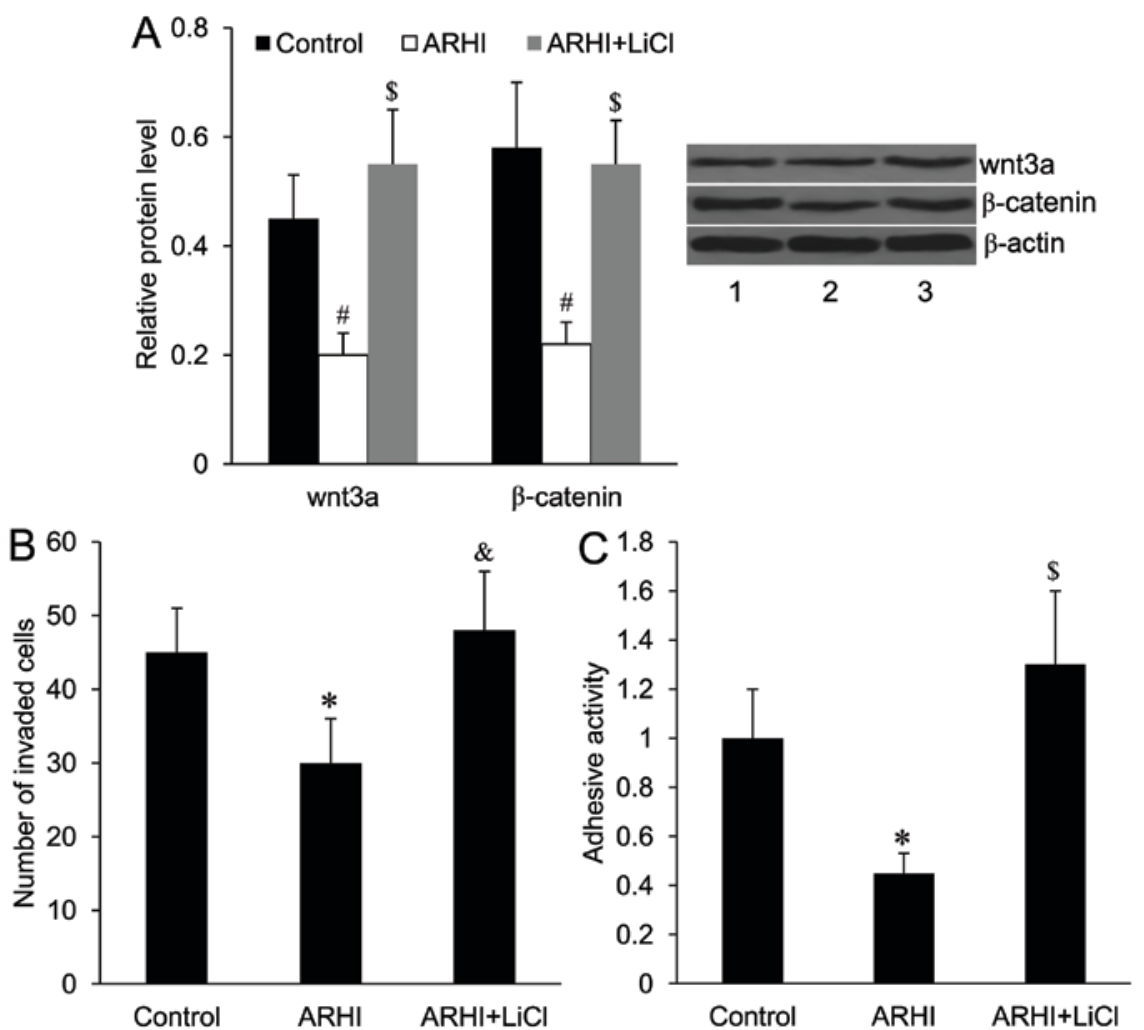

Figure 5. Wnt/ $\beta$-catenin signaling activation and the effect of ARHI on HCT116 cell invasion and adhesion. (A) Protein expression levels of wnt3a and $\beta$-catenin, relative to $\beta$-actin, in HCT116 cells following transfection with the ARHI-pcDNA3.1 plasmid and treatment with LiCl. (B) Cell invasion ability of HCT116 cells following transfection with the ARHI-pcDNA3.1 plasmid and treatment with LiCl. (C) Cell adhesion ability of HCT116 cells following transfection with the ARHI-pcDNA3.1 plasmid and treatment with LiCl. Data are expressed as the mean + standard deviation $(\mathrm{n}=3)$. ${ }^{*} \mathrm{P}<0.05$ and ${ }^{\#} \mathrm{P}<0.01$ vs. the control; ${ }^{\&} \mathrm{P}<0.05$ and ${ }^{\mathrm{S}} \mathrm{P}<0.01$ vs. ARHI. Lane 1, control; lane 2, ARHI; lane 3, ARHI + LiCl; ARHI, aplysia ras homolog I; LiCl, lithium chloride.

EMT is a process in which epithelial cells lose their cell polarity and cell-cell adhesion, and gain the invasive and metastatic properties to become mesenchymal stem cells (23). EMT has been demonstrated to occur in the initiation of metastasis for cancer progression $(12,13,24-26)$. Loss of E-cadherin is considered to be a fundamental event in EMT (27). N-cadherin and vimentin are mesenchymal cell markers, and they are closely related to cell invasion $(28,29)$. In the present study, western blot analysis for E-cadherin, $\mathrm{N}$-cadherin and vimentin protein expression was performed to investigate the effect of ARHI on EMT in colon cancer cells. It was demonstrated that ARHI overexpression led to the increased expression of E-cadherin and the decreased expression of $\mathrm{N}$-cadherin and vimentin. These findings indicated that ARHI could inhibit EMT in colon cancer cells.

The wnt/ $\beta$-catenin signaling pathway has critical roles in embryonic development and carcinogenesis (30-34). It has been demonstrated that the wnt/ $\beta$-catenin signaling pathway regulates EMT in cancer (35-37). In a study by Yu et al (21), it was indicated that ARHI could induce apoptosis in renal cancer cells and it exerted its effect via the $\beta$-catenin signaling pathway. In the present study, it was demonstrated that ARHI 

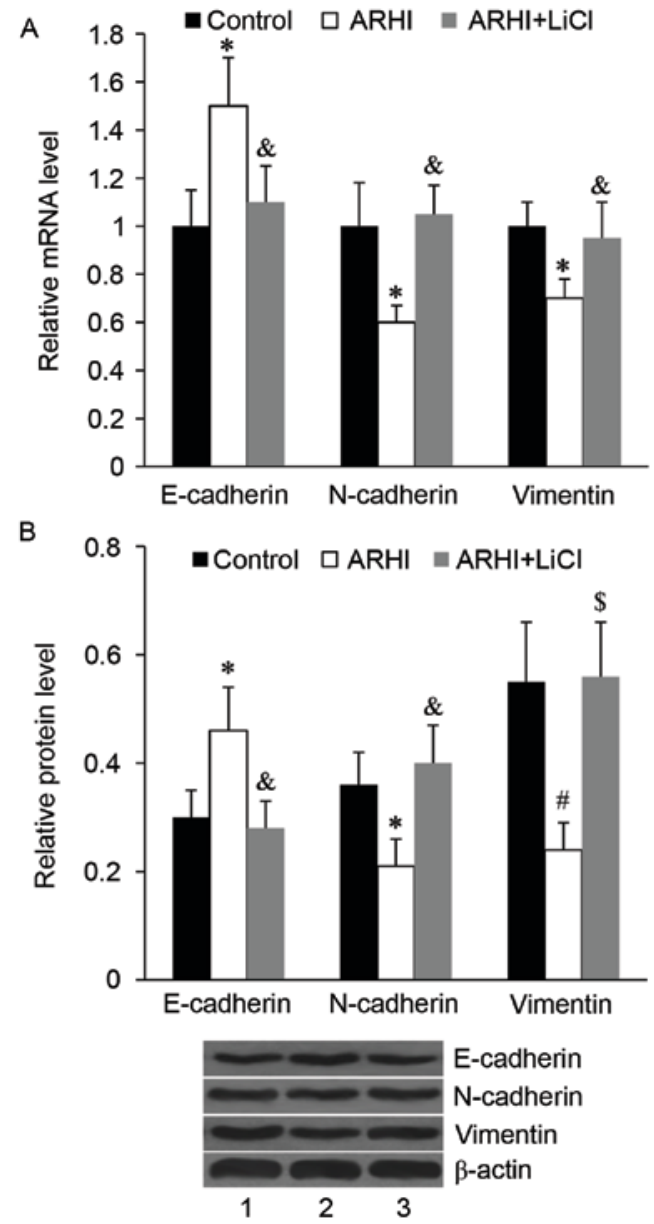

Figure 6. Wnt/ $\beta$-catenin signaling activation and the effect of ARHI on EMT in HCT116 cells. (A) Relative mRNA expression levels of EMT markers following transfection with the ARHI-pcDNA3.1 plasmid and treatment with $\mathrm{LiCl}$. (B) Relative protein expression levels of EMT markers following transfection with the ARHI-pcDNA3.1 plasmid and treatment with $\mathrm{LiCl}$. Expression levels are relative to $\beta$-actin. Data are expressed as the mean + standard deviation $(n=3) .{ }^{~} \mathrm{P}<0.05$ and ${ }^{~} \mathrm{P}<0.01$ vs. the control; ${ }^{\&} \mathrm{P}<0.05$ and ${ }^{\$} \mathrm{P}<0.01$ vs. ARHI. Lane 1 , control; lane 2, ARHI; lane 3, ARHI + LiCl; ARHI, aplysia ras homolog I; EMT, epithelial-mesenchymal transition; $\mathrm{LiCl}$, lithium chloride.

overexpression suppressed the wnt $/ \beta$-catenin signaling pathway by downregulating the expression of wnt $3 \mathrm{a}, \beta$-catenin, as well as Axin 2, c-Myc and cyclin D1, which are important downstream targets of wnt $/ \beta$-catenin signaling. Furthermore, it was observed that the activation of wnt $/ \beta$-catenin signaling in colon cancer cells by $\mathrm{LiCl}$ treatment could attenuate the effect of ARHI on EMT, and colon cancer cell invasion and adhesion. These results indicated that ARHI inhibits colon cancer cell invasion, adhesion and EMT, at least partially, via the suppression of the $\mathrm{wnt} / \beta$-catenin signaling pathway.

In conclusion, the present study was the first to determine the effects of ARHI on colon cancer cell invasion and adhesion. Results demonstrated that ARHI could inhibit colon cancer cell invasion and adhesion through suppressing EMT, and these effects were achieved, at least partially, via the suppression of the wnt $/ \beta$-catenin signaling pathway. The present study provided the molecular basis for the role of ARHI in colon cancer, and may help in developing novel therapeutic approaches for colon cancer.

\section{References}

1. Bartczak-Tomczyk M, Sałagacka A, Mirowski M, Jeleń A and Balcerczak E: Quantitative analysis of FJ 194940.1 gene expression in colon cancer and its association with clinicopathological parameters. Contemp Oncol (Pozn) 17: 45-50, 2013.

2. Cunningham D, Atkin W, Lenz HJ, Lynch HT, Minsky B, Nordlinger B and Starling N: Colorectal cancer. Lancet 375: 1030-1047, 2010

3. Gulbake A, Jain A, Jain A, Jain A and Jain SK: Insight to drug delivery aspects for colorectal cancer. World J Gastroenterol 22: 582-599, 2016.

4. Cunningham D, Atkin W, Lenz HJ, Lynch HT, Minsky B, Nordlinger B and Starling N: Colorectal cancer. Lancet 375: 1030-1047, 2010.

5. Yu Y, Xu F, Peng H, Fang X, Zhao S, Li Y, Cuevas B, Kuo WL, Gray JW, Siciliano M, et al: NOEY2 (ARHI), an imprinted putative tumor suppressor gene in ovarian and breast carcinomas. Proc Natl Acad Sci USA 96: 214-219, 1999.

6. Luo RZ, Fang X, Marquez R, Liu SY, Mills GB, Liao WS, Yu Y and Bast RC: ARHI is a Ras-related small G-protein with a novel $\mathrm{N}$-terminal extension that inhibits growth of ovarian and breast cancers. Oncogene 22: 2897-2909, 2003.

7. Chen J, Shi S, Yang W and Chen C: Over-expression of ARHI decreases tumor growth, migration, and invasion in human glioma. Med Oncol 31: 846, 2014.

8. Wu X, Liang L, Dong L, Yu Z and Fu X: Effect of ARHI on lung cancer cell proliferation, apoptosis and invasion in vitro. Mol Biol Rep 40: 2671-2678, 2013.

9. Bao JJ, Le XF, Wang RY, Yuan J, Wang L, Atkinson EN, LaPushin R, Andreeff M, Fang B, Yu Y and Bast RC Jr: Reexpression of the tumor suppressor gene ARHI induces apoptosis in ovarian and breast cancer cells through a caspase-independent calpain-dependent pathway. Cancer Res 62: 7264-7272, 2002.

10. Tang HL, Hu YQ, Qin XP, Jazag A, Yang H, Yang YX, Yang XN, Liu JJ, Chen JM, Guleng B and Ren JL: Aplasia ras homolog member $\mathrm{I}$ is downregulated in gastric cancer and silencing its expression promotes cell growth in vitro. J Gastroenterol Hepatol 27: 1395-1404, 2012.

11. Wang W, Chen L, Tang Q, Fan Y, Zhang X and Zhai J: Loss of ARHI expression in colon cancer and its clinical significance. Contemp Oncol (Pozn) 18: 329-333, 2014.

12. Thiery JP: Epithelial-mesenchymal transitions in tumour progression. Nat Rev Cancer 2: 442-454, 2002.

13. Brabletz T, Hlubek F, Spaderna S, Schmalhofer O, Hiendlmeyer E, Jung A and Kirchner T: Invasion and metastasis in colorectal cancer: Epithelial-mesenchymal transition, mesenchymal-epithelial transition, stem cells and beta-catenin. Cells Tissues Organs 179: 56-65, 2005.

14. Nelson WJ and Nusse R: Convergence of Wnt, beta-catenin, and cadherin pathways. Science 303: 1483-1487, 2004.

15. Tang B, Tang F, Wang Z, Qi G, Liang X, Li B, Yuan S, Liu J, Yu S and He S: Overexpression of CTNND1 in hepatocellular carcinoma promotes carcinous characters through activation of Wnt/ $\beta$-catenin signaling. J Exp Clin Cancer Res 35: 82, 2016.

16. Qi L, Sun B, Liu Z, Cheng R, Li Y and Zhao X: Wnt3a expression is associated with epithelial-mesenchymal transition and promotes colon cancer progression. J Exp Clin Cancer Res 33: 107,2014

17. Livak KJ and Schmittgen TD: Analysis of relative gene expression data using real time quantitative PCR and the 2(-Delta Delta C(T)) method. Methods 25: 402-408, 2001.

18. Yu Y, Xu F, Peng H, Fang X, Zhao S, Li Y, Cuevas B, Kuo WL, Gray JW, Siciliano M, et al: NOEY2 (ARHI), an imprinted putative tumor suppressor gene in ovarian and breast carcinomas. Proc Natl Acad Sci USA 96: 214-219, 1999.

19. Li Y, Liu M, Zhang Y, Han C, You J, Yang J, Cao C and Jiao S: Effects of ARHI on breast cancer cell biological behavior regulated by microRNA-221.Tumour Biol 34: 3545-3554, 2013.

20. Lu Z, Luo RZ, Peng H, Rosen DG, Atkinson EN, Warneke C, Huang M, Nishmoto A, Liu J, Liao WS, et al: Transcriptional and posttranscriptional down-regulation of the imprinted tumor suppressor gene ARHI (DRAS3) in ovarian cancer. Clin Cancer Res 12: 2404-2413, 2006.

21. Yu J, Kong CZ, Zhang Z, Zhan B and Jiang ZM: Aplasia Ras homolog member I expression induces apoptosis in renal cancer cells via the $\beta$-catenin signaling pathway. Mol Med Rep 11: 475-481, 2015. 
22. Krakhmal NV, Zavyalova MV, Denisov EV, Vtorushin SV and Perelmuter VM: Cancer invasion: Patterns and mechanisms. Acta Naturae 7: 17-28, 2015.

23. Kalluri R and Weinberg RA: The basics of epithelial-mesenchymal transition. J Clin Invest 119: 1420-1428, 2009.

24. Thiery JP, Acloque H, Huang RY and Nieto MA: Epithelial-mesenchymal transitions in development and disease. Cell 139: 871-890, 2009.

25. Drasin DJ, Robin TP and Ford HL: Breast cancer epithelial-to-mesenchymal transition: Examining the functional consequences of plasticity. Breast Cancer Res 13: 226, 2011.

26. Bates RC and Mercurio AM: The epithelial-mesenchymal transition (EMT) and colorectal cancer progression. Cancer Biol Ther 4: 365-370, 2005.

27. Prieto-García E, Díaz-García CV, García-Ruiz I and Agulló-Ortuño MT: Epithelial-to-mesenchymal transition in tumor progression. Med Oncol 34: 122, 2017.

28. Mendez MG, Kojima S and Goldman RD: Vimentin induces changes incell shape, motility, and adhesion during the epithelial to mesenchymal transition. FASEB J 24: 1838-1851, 2010.

29. Zhang X, Liu G, Kang Y, Dong Z, Qian Q and Ma X: N-cadherin expression is associated with acquisition of EMT phenotype and with enhanced invasion in erlotinib-resistant lung cancer cell lines. PLoS One 8: e57692, 2013.

30. Li J, Ji L, Chen J, Zhang W and Ye Z: Wnt/ $\beta$-Catenin signaling pathway in skin carcinogenesis and therapy. Biomed Res Int 2015: 964842, 2015.
31. Sokol SY: Spatial and temporal aspects of Wnt signaling and planar cell polarity during vertebrate embryonic development. Semin Cell Dev Biol 42: 78-85, 2015.

32. Sebio A, Kahn M and Lenz HJ: The potential of targeting Wnt $/ \beta$-catenin in colon cancer. Expert Opin Ther Targets 18: 611-615, 2014.

33. Holland JD, Klaus A, Garratt AN and Birchmeier W: Wnt signaling in stem and cancer stem cells. Curr Opin Cell Biol 25: 254-264, 2013

34. Tanaka SS, Kojima Y, Yamaguchi YL, Nishinakamura R and Tam PP: Impact of WNT signaling on tissue lineage differentiation in the early mouse embryo. Dev Growth Differ 53: 843-856, 2011.

35. Shan S, Lv Q, Zhao Y, Liu C, Sun Y, Xi K, Xiao J and Li C: $\mathrm{Wnt} / \beta$-catenin pathway is required for epithelial to mesenchymal transition in CXCL12 over expressed breast cancer cells. Int J Clin Exp Pathol 8: 12357-12367, 2015.

36. Ghahhari NM and Babashah S: Interplay between microRNAs and $\mathrm{WNT} / \beta$-catenin signalling pathway regulates epithelial-mesenchymal transition in cancer. Eur J Cancer 51: 1638-1649, 2015.

37. Li H, Wang Z, Zhang W, Qian K, Liao G, Xu W and Zhang S: VGLL4 inhibits EMT in part through suppressing Wnt/ $\beta$-catenin signaling pathway in gastric cancer. Med Oncol 32: 83, 2015. 